\title{
Time Biases: Exploring the Work-Life Balance of Single Nigerian Managers and Professionals
}

\begin{abstract}
Purpose - This study investigates the overarching ideology of work-life balance (WLB) or conflict as predominantly being a work-family affair. Based on a Nigerian study, and using organisational justice as a theoretical lens, it explores perceived fairness in accessing familyfriendly policies by managers and professionals who are single and do not have children - a workgroup conventionally ignored in research on WLB.
\end{abstract}

Design/methodology/approach - Relying on an interpretivist approach, the dataset comprises of interviews with 24 bank managers and 20 medical doctors working in Nigeria.

Findings - Our findings highlight employers' misconceptions concerning the non-work preferences and commitments of singles as well as an undervaluation by employers of their non-work time. Conceptualised as 'time biases', such time is routinely invaded by the organisation, with profound implications for perceptions of fairness. This fosters backlash behaviours with potential detrimental effects in terms of organisational effectiveness.

Research limitations/implications - The study is limited to investigating the WLB of singles in high-status roles, namely banking and medical careers. Future research may examine the experiences of a more diverse range of occupations. The sample comprises heterosexual, nevermarried professionals, whose experiences may differ from other categories of single workers, such as childless divorced people, widows, non-heterosexual singles, and partners who have no children.

Practical implications - In order to avoid counterproductive behaviours in the workplace, WLB policies should not only focus on those with childcare concerns. Inclusive work-life policies for other household structures, such as single-persons, are necessary for improving overall organisational wellbeing.

Originality/value - The majority of WLB studies have been undertaken in Western and Asian contexts, to the neglect of the Sub-Saharan African experience. Additionally, research tends to focus on WLB issues on the part of working parents, overlooking the difficulties faced by singles.

Authors

Emeka Oruh: University of Portsmouth

Babatunde Akanji: Elizade University, Ondo State Nigeria.

Chima Mordi: Brunel University, London

Ruth Simpson: Brunel University London

Toyin Adisa: University of East London 


\section{Introduction}

There has been a growing global interest in academic research, government policies, labour legislation, and corporate policies relating to the importance of balancing work and non-work obligations (Kelly et al., 2014). WLB studies are largely concerned with the demands inherent in managing work and non-work-related activities (Lewis and Cooper, 2005) and the implications for organisations in enabling autonomy in terms of where, when, and how people achieve acceptable integration between both domains (Visser and Williams, 2006). However, while the concept in general is perceived as addressing an overall sense of harmony in the lives of working adults (Clark et al., 2004), its propositions often prioritise the experiences of working mothers, dual-income couples (Lewis and Humbert, 2010), and married workers with familial and home responsibilities (Mushfiqur et al., 2018) to the neglect of childless singles. Further, while significant research has been undertaken on WLB in Western developed nations (Wilkinson et al., 2017) and Asian countries (Rajadhyaksha, 2012), little is known about WLB challenges and experiences in an African context such as Nigeria.

Despite the paucity of research on the WLB of singles (Casper and DePaulo, 2012), WLB is just as important to them as it is to workers who are married and have familial responsibilities (Casper et al., 2016). As Collins (2008) has argued, certain jobs (e.g. those requiring extensive travel) may prioritise hiring single people because they are assumed to be willing and able to focus on work and have no other demands on their time. This raises issues regarding the WLB of single workers and questions the fairness of organisational policies that prioritise the needs of those with family roles. These issues are particularly pertinent in Nigeria, which has experienced an increase in single working individuals, and where some key professions are encountering pressures in terms of work intensity and excessive work demands (Nigerian Data Portal, 2019).

Our research is based on a study of single, childless professionals and managers (referred to thereafter as 'singles') in banking and medical practice. It focuses on issues of fairness and is informed by organisational justice theory. It addresses the following questions: How do single professionals and managers in banking and medical practice perceive the fairness of their organisation's WLB management policies, and how does their perception of its fairness affect their work attitudes and behaviours?

Our findings highlight employer misconceptions regarding a perceived low level of non-work commitments on the part of singles and 'time biases' as reasons for the employers' undervaluation of singles' non-work time. Such time is routinely invaded by the organisation, with profound implications for perceptions of fairness and organisational effectiveness. Based on these findings, we argue that there is a need to understand the WLB needs of singles and the significance of contextual and cultural sensitivities when employers assess the work and non-work time of single childless professionals and managers, this we believe extends the development of WLB research.

\section{Work-Life Balance and Perceptions of Fairness towards Work-Life Policies}

WLB expectations are related to demands inherent in trying to reconcile work and non-work affairs satisfactorily (Gatrell and Cooper, 2008). According to Shockey et al. (2018), how people manage their work and family lives are usually assessed from three main perspectives: the direction of influence (whether work-to-family or family-to-work), scope of influence (whether it is positive, such as enrichment, or negative, resulting in conflict), and the nature of the influence (e.g. spillover or boundary management experiences). Although some scholars have suggested that there is no precise definition of the concept (Brough and Kalliath, 2009), Manfredi and Holliday (2004) define WLB as the notion that work and non-work matters 
should be seen less as competing priorities but rather as complementary elements of a full life. Clark (2000) further suggests that WLB means functioning both at work and at home with minimum conflict.

The basis of most WLB research is the need for family-friendly policies and the need to legitimise non-standard work in order to cater, in particular, for those with family obligations (Feeney and Stritch, 2017). However, as more critical reviews of work-family studies emerge, scholars have argued for greater inclusivity (Özbilgin et al., 2010). Consequently, the more encompassing term 'work-life' as distinct from 'work-family' has gained widespread recognition and has paved the way for the universal adoption of more inclusive terminologies, such as work-life enrichment (Greenhaus and Powell, 2006), work-life facilitation (Rotondo and Kinchaid, 2008), and boundary management (Kossek et al., 2012).

Although the term 'WLB' remains widely used in organisational studies, it is a contested term in the literature. While popular WLB discourse emphasises the need to make the workplace more flexible to help employees, as responsible agents, pursue a better work-life integration, the conceptual conversations and policy implications of WLB appear to exclude demographic diversity (Wilkinson et al., 2017). Work-life debates tend to focus on contested claims for social justice in redressing matters arising from the gendered division of labour, including family constraints encountered by women seeking economic independence and self-worth (Agarwal and Lenka, 2015). Consequently, Özbilgin et al. (2010, p. 2) argue that WLB debates have been grounded on assumptions that have confined research 'to a narrow group of employees and traditional family structures', overlooking the significance of particular contextual conditions. However, Western-based organisations in particular are gravitating towards more workplace diversity, where a commitment to equal opportunities is necessitating the implementation of more inclusive WLB policies. This issue becomes more pressing in the context of an increase in one-person households (e.g. from later marriages, rising divorce, and reduced fertility levels) in both developed countries (Yakes, 2018) and developing countries such as Iran, The Philippines, Pakistan, Vietnam, and India (Yeung and Cheung, 2014).

The few studies that have addressed the issue suggest that childless single employees experience work-life stress in their daily lives (Chander et al., 2004). Brummelhuis and Van Der Lippe (2010) posit that the work-life stress of unmarried professionals is exacerbated by long working hours with unpredictable closing times, indicating particular time pressures for this demographic set. Many employers see unmarried employees as having no family responsibilities, seeing 'family' solely in terms of childcare and overlooking responsibilities to other family members. This suggests that employers may evaluate the availability of work time and importance of non-work time differently, dependent in part on employees' parental status. As Zheng et al. (2015) have pointed out, organisations with 'distorted views' of WLB in relation to their employees are often seen as tolerating organisational inequalities. Considered through organisational justice (OJ) theory (Greenberg, 1987), this highlights the significance of perceptions of fairness in the workplace and how employees judge the fairness of organisational policies and practices.

There are three distinct, though overlapping, theoretical constructs within OJ. These are: distributive justice based on equity principles (perceived fairness in allocations or outcomes that some employees obtain while others do not), procedural justice (elements of fairness in decision-making processes leading to particular outcomes), and interpersonal justice (quality of dignity and respect in employees' treatment by organisational authority figures) (Kovačević et al., 2013). The concept of OJ has been used widely to assess a range of organisational behaviour outcomes, workplace practices, and policies (Wilkinson et al., 2018). These include research on performance appraisals (Erdogan, 2002), disciplinary procedures (Cole and 
Latham, 1997), pay and reward systems (Bloom, 2004) and other WLB issues affecting nurses (Nelson and Tarpey 2010). However, very few studies have drawn on OJ theory to investigate the WLB of singles. One exception is Wilkinson who explored the phenomenon from the UK context (Wilkinson et al., 2017; 2018). Further, there are no studies that focus on OJ and the WLB of singles in a non-western, African context which leaves their experiences undertheorised. Through an investigation of two under-researched prominent professions (in medical practice and banking sector), we contribute to the development of OJ theory by explaining fairness perceptions in accessing WLB policies by Nigerian singles and behavioural outcomes therefrom. 


\section{The Study Context}

Nigeria has a population of about 190 million people spread across over 250 ethnic groups (National Population Commission of Nigeria, 2017). Traditionally, there is a cultural convergence among various tribes, and so Nigeria is best described as a collectivist society (Hofstede, 2001). This is manifest in Nigeria's social structures, which reveal people's longterm commitment to in-group membership, to groups such as their immediate family, extended families, and extended relationships. The country is also considered a low and middle-income economy, despite having the largest economic base in the West African region.

Two of the most prominent white-collar jobs in Nigeria are in the medical and banking sectors. The Nigerian healthcare sector, comprised of private, public, and government hospitals, are responsible for providing healthcare services. Its affairs are regulated by the Nigerian Medical and Dental Council. Records show that Nigeria has the largest number of doctors in Africa (Adisa et al., 2017). However, Nigeria's political instability, economic downturn, and poor working conditions are causing many professionals, especially medical doctors, to migrate to 'greener pastures' with better career and WLB prospects (Mushfiqur et al., 2018). The Nigerian banking sector has also faced numerous challenges over the years. The weak capital base of most banks led the Central Bank of Nigeria (CBN) to take drastic steps to reposition the Nigerian banking institutions after the liquidation of several banks in the 1990s (Mordi et al., 2013). This resulted in mergers and acquisitions leading to a large reduction in the number of banks, after CBN raised the minimum capital base from 2 billion to 25 billion Naira (Adegbaju and Olokoyo, 2008). However, these revolutionary changes brought about stronger workforce planning and stricter HR control measures adopted by the few well recapitalised banks, which downsized their workforce as a result of the restructuring (Kirfi and Abubakar, 2014). Long working hours, demanding work shift patterns, and high level of job insecurity raised questions about the quality of the WLB of employees in the industry.

\section{Methodology}

This qualitative study is guided by interpretive constructionism, which allows researchers to discover rich narratives from peoples' lived experiences (Saunders et al., 2012). This approach was chosen to gain in-depth understanding of the researched phenomenon (Cresswell, 2013).

\section{Data Collection}

Relying on subjective judgements, a non-probabilistic purposive sampling was used to recruit a total number of 44 middle-line bank managers and medical doctors. All participants were heterosexual and never-married professionals. With the exception of seven women who lived with family members, all others lived alone in rented apartments. Purposive sampling was selected on the assumption that qualitative researchers should have reasonable knowledge of the sample size to be used and target those samples sought (Patton, 2015). Participants were solicited through emails, personal contacts, and referrals, using the snowballing approach (Saunders et al., 2012). The banks and hospitals visited were located in four different commercial cities in Nigeria: Lagos, Abuja, Port Harcourt, and Benin City. In total, 20 doctors $(45 \%)$ were employed in the three public hospitals visited in Abuja, Lagos and Benin, while the rest $24(55 \%)$ located at Lagos, Abuja, Port Harcourt, and Benin City work in four different banks as middle-line managers. Both genders were represented in our sample size. The doctors comprised of 10 general practitioners (GPs), 4 consultants in various specialist fields of medicine such as clinical surgery, paediatrics, dermatology and dentistry while the remaining 6 were interns (physicians in training). All the participants in the banking sector held various managerial positions ranging from personnel managers, investors managers, head of operations, sales, product, ICT, logistics to branch managers. In order to fulfil our promise of 
confidentiality, pseudonyms were used to represent the interviewees who were labelled (Participant 1-44) for the purpose of our study.

Furthermore, each participant's eligibility was based on length of time working with their current employers (a minimum of one year), age (between 25-40 years old), and marital status (single, never married, and childless). Each semi-structured interview lasted 45 to 60 minutes after prior consent was obtained from participants and their employers. The interview style, based on open-ended questions, allowed for flexibility in discussions and exploration of individual perceptions. Interviews were conducted on-site so that research findings could be contextualised. In terms of study reliability, the researchers met from time to time to compare notes and ensure all interview protocols were completely covered so that dependability on the collected data would not be compromised (Guba and Lincoln, 1994).

Interview themes covered broad areas including how WLB is understood, meanings given to the term, organisational policies relating to WLB, and how these are perceived. Sessions were recorded electronically with consent from participants. After 39 participants had been interviewed, it was felt that the 'saturation point' had been reached because no further information was added that enhanced the findings from the study (Bowen, 2008). To confirm, a further five interviews were undertaken to corroborate existing themes.

\section{Data Analysis}

Data were transcribed immediately after the interviews. In an iterative style, we analysed and transcribed our data by going back and forth between the data using a thematic analysis procedure (TAP). TAP is a qualitative design employed to identify, analyse, and report patterns (themes) within datasets (Braun and Clarke, 2006). This was done by utilising three major steps following Pratt et al.'s (2006) pattern.

First, we created provisional categories via first-order codes. In so doing, we began a data reduction process through open coding, which involves analysing textual content and creating a word or phrase that symbolically assigns a salient, summative, and essence-capturing attribute of interview extracts directly addressing our research inquiry (see Figure 2 below).

\section{Insert Figure 1 here}

Following the qualitative approach recommended by Miles and Huberman (1994), we used a contact summary form to record provisional categories revealed in interview extracts at each point in time. For example, there were data fragments that related to one of the representative questions asked: 'What are the factors constraining you from having satisfactory WLB as a bank manager/doctor?' In addressing this question, 'tentative descriptions' from data chunks suggest unfair practices based on their organisation's perception of WLB of singles (see illustrative quotes in Figure 1). After codes were named and categories were constructed, we meticulously reviewed the interview data to ensure important narratives, accounts, and ensuing extracts fitted each category appropriately.

Second, we consolidated first-order codes to create theoretical categories. This was accomplished by consolidating first-order codes that emerged from interview data based on the participants' concerns about their WLB management and fairness perceptions. This made the first-order coding 'more theoretical and more abstract' (Pratt et al., 2006, p. 240). In the third and final step, we consolidated our conceptual categories in a bid to generate theoretical explanations for the occurrence of the phenomenon under study. Key themes were unveiled pertaining to perceptions of WLB and organisations' perceived approach in terms of who is seen as more deserving, and the implications for employees' feelings of fairness and attitudes 
towards work. A process of cross-comparison and validation of conceptual categories continued until we reached a consensus on the main themes of the study, grounded in the data. These themes are outlined below.

\section{Perceptions of WLB}

Participants generally defined WLB as the ability to balance work with leisure and personal commitments. Despite the pressures of heavy workloads, participants were committed to recreational pursuits, including sports and other social activities. Some participants said WLB includes being able to balance work with career-enhancing education and participation in volunteer work. As in other accounts, these leisure and non-work activities were perceived as discretionary time left 'free' from work.

For me, WLB means the ability to reconcile work and personal needs other than family commitments, like physical exercise, sports, and recreation (Participant 41).

However, concerning fairness, most felt they were required to meet higher expectations and heavier work demands (see Figure 1) because of their single status and that employers had misconceived ideas about their private affairs. As one female doctor commented:

There is this general assumption in my hospital that since I am not a married woman, WLB should not be my primary concern.

From her assessment, the management team were 'oblivious' to her wider family responsibilities (which she described as 'intrinsically rewarding experiences of life') such as the requirement to attend marriages, child dedications, and birthday parties. As we explore below, these attitudes on the part of employers draw together notions of justice with assumptions of singles' availability to work and a devaluation of their non-work time.

\section{WLB policies, Favouritism, and Notions of Singles Non-Work Time}

Nigeria is unlike Western countries (e.g. the UK and the US), where there are numerous WLB policies available, including flexible work options, specialised leave policies, and dependent care benefits, such as child support, crèche, and adult care benefits (Mordi et al., 2013). The employing organisations within the study had only a few flexible work systems (e.g. adjusted working hours, shortened workweek, job sharing and casual leave allowance). Given that few WLB policies are available, there were strong beliefs on the part of participants that managerial biases and ethnic favouritism affect decisions relating to whom the limited WLB policies available are offered and their belief that organisations routinely undervalue their non-work time. In terms of the former and in addition to responses from the interviewees outlined in Figure 1, the data highlights a pervasive perception of favouritism and unfair treatment, despite claims that the allocation of benefits are made strictly in the order in which applications are made:

The reason why I experience work-life imbalance is because I am always deprived of the right to use flexible shifts and alternate workweeks [...] Our HR office keeps informing me that the policies are always utilised on a first come, first served basis, but I noticed that flexible work patterns and job sharing are reserved exclusively for those with children (Participant 38).

It gives me some concern to know how some senior HR managers are comfortable with their people, especially the married ones, from their ethnic area and are favourably disposed to prioritising their work-family needs at the expense of those of us [...]. Our tribal sentiments in this country are really disturbing (Participant 30 ).

These findings confirm evidence from Wilkinson et al.'s (2017) study, which reveals the extent to which organisational flexible working schedules focus on the needs of those with nuclear 
families. As referred to above, the majority of participants reported instances of differential treatment due to their single status that impaired their ability to balance their work-life affairs.

Eby et al. (2004) have shown how employees with children are often seen as more responsible than single employees (and are rewarded accordingly in terms of WLB benefits), and issues were raised here about employers' misconceived notions about singles' time (see Figure 1). Organisational practices and decisions seemed to be based on the idea that singles' time was more freely available for work-related tasks and that their non-work commitments were of less consequence:

I believe having WLB means my ability to coordinate my work and private life seamlessly, but it seems my hospital has this impression that my being single implies I have all the time to dedicate to work and build my career (Participant 1).

WLB is good if my bank will stop making me work long stressful hours and weekends all because I'm still single (Participant 44).

Half of the participants spoke extensively of being burdened with demanding shifts which they saw, in distributive justice terms, as an unfair allocation of work. Some doctors complained that, in accordance with norms of professional practice, they felt compelled to take on extra tasks (see Figure 2) to the detriment of their personal commitments. With clear relevance for procedural justice, issues were raised about the fairness of the decision-making process whereby single professionals were seen to be more available and required to work longer hours:

A major problem hindering my WLB is the longer period I'm made to spend working at the expense of attending to other germane issues of my life [...] it is so difficult to even get into a serious relationship despite parental pressures for marriage (Participant 32).

I have strong impressions that the hospital management feels that single doctors, unlike those married, will normally have limited non-work responsibilities and should be able to work any shift pattern offered. This is not right, it makes my life blurry (Participant 22).

Experiences of coercion ('I'm made to spend [time] working') and perceptions of injustice ('this is not right') underpin some of the acute challenges encountered by single employees (summarised in the first-order codes). The female participants in the study highlighted these challenges in terms of the difficulties of forging potential intimate relationships, and the struggle to manage the boundaries between their work and private domains (see Figure 1). According to boundary theory, people tend to manage, maintain, and create boundaries between their work and personal lives by means of segmenting and integrating both domains (Nippert-Eng, 1996). Our findings suggest singles experience boundary struggles ('it makes my life blurry') based on misconceptions on the part of employers concerning singles' availability, and their presumption that singles without dependent children have no family concerns.

Singles' concerns can include health-related issues - a factor that is not normally associated with WLB and which further highlights a lack of distributive justice compared to married colleagues:

For me, WLB is about having time to work and take care of myself. I've been diagnosed with high blood pressure and was told that one of the possible causes is prolonged physical inactivity [...], but I struggle to have time to take care of myself and [am] stressed because it appears my bank feels WLB matters are only for those with children and not on merit (Participant 31).

My employer always give me the impression that time for my private life including even health care concerns can always wait, which stems out of the belief that I don't have any other care responsibilities other than myself (Participant 21). 
Assumptions concerning the greater work availability of singles (see Figure 1) and that personal life matters 'can always wait' - to the point that singles struggle to manage health issues - support strong feelings of unfairness. These encompass a lack of distributive justice in a differential allocation of work tasks that places an extra burden on singles. It also implicates a lack of procedural justice in the decision-making processes that lead to these outcomes, and a lack of interpersonal justice in the apparent lack of concern for and neglect of single employees' well-being, where married workers are, in the words of the participant above, 'given more attention'. This finding resonates with Wilkinson et al.'s (2017) study, which posits that singles are assumed to have more time available for work and that their non-work time is seen as less important when compared to employees with families, so that potential nonwork time of singles can be easily 'invaded', indicative of a 'time biases' on the part of employers.

Further, as Antoniou et al. (2009) found, single employees experience various stressors simply because their employers fail to take a broader view of what constitutes 'life' than fulfilling childcare roles. These findings support critiques of WLB literature as failing to foreground contextually informed meanings and failing to legitimise singles' non-work affairs. There is an assumption that singles' non-work commitments are unimportant, which underpins perceptions of ill-treatment from those in authority. Overall, we can see how procedural justice issues (evident in the way decisions are made on the basis of group belonging and married status rather than merit) intersect with interactional (in)justice in that singles are afforded less consideration, dignity, and respect from those with decision-making powers.

\section{Backlash Effects}

According to our data, perceptions of managerial biases in relation to WLB issues among singles have profound implications for 'backlash' attitudes and behaviours (i.e. negative reactions that are potentially counterproductive to organisational performance) (Beauregard, 2014). This was evident through low morale, demotivation, lower commitment, and greater feelings of stress:

I really feel deprived when my short casual leave request between the Christmas and New Year breaks are declined by my superiors, while similar requests from other branch managers who are married are approved [...]. This is the only time I have in the year to visit my parents, and siblings [...]. The most annoying part is that these married folks are also paid holiday bonuses [...]. These practices stress me [...] (Participant 25).

Giving flexible work preferences to some people only because they have parental responsibilities at the detriment of others, like me, sometimes causes workplace disaffection and segregation [...] [it] lowers my morale and sense of commitment to my job, because we know how stressful banking job in Nigeria is, irrespective of marital status (Participant 34).

Our senior registrar will not hear WLB and does not care about what happens to your life outside work but is considerate when it comes to those with children. This attitude is very demotivational, particularly to singles of marriageable ages but [who] don't have time to go on decent dates (Participant 5).

The undervaluing of the non-work time of singles and the practices of favouritism outlined above (which reward those with children to the exclusion of singles) lead to a profound sense of injustice. This can be seen in the participants' comments concerning their feelings of being 'deprived' and 'disaffected' and with descriptions of such practices as 'demotivational'. These negative reactions are likely to have a detrimental effect on the organisation. Several studies point out that single workers without dependent children also have families (Casper and DePaulo, 2012; Casper et al., 2016). Participant 25 above spoke of being unable to visit parents, 
siblings, and other relatives at a key time of the year. Unfortunately, the typical use of the word 'family' in the 'work-family' literature does not cover these categories; rather, the literature refers solely to employees with spouses and children (Casper and DePaulo, 2012). As Abubakar and Bagley (2016) state, despite formalised HR directives on the need to implement WLB policies for all employees, middle-line managers often lack the requisite knowledge and fail to embrace ethical practices. Instead, it reflects peoples' close commitment to in-group membership and the primacy afforded to family obligations in the Nigerian context, as decisions are made based on childcare responsibilities, ethnic allegiance, and favouritism.

\section{Discussion and Conclusion}

This paper explored the different meanings of WLB and perceptions of fairness regarding access to work-life policies among singles in Nigeria. The experiences of single professionals have been largely overlooked in the work-life literature, where priority has been given to employees with children (Özbilgin et al., 2010). Situated in a national context (Nigeria) that has been neglected in favour of Western-based research, the study has focused on two sectors (the banking and medical practice) that have been subject to specific pressures and work intensifications, making WLB a pertinent area of inquiry. As such, our study has made important empirical and theoretical contributions.

In terms of the former, our findings show that perceptions of singles' WLB largely conform to existing conceptualisations that see WLB as the ability to balance, in harmonious terms, work and other leisure and personal commitments. Our data points to a wide range of activities that are seen to comprise the non-work domain, including volunteer work, personal development, and basic health care. Participants highlight critical challenges in managing WLB, not only in terms of combining work with leisure and wider family obligations, but also in relation to managing personal wellbeing.

Further, our data foregrounds how issues of distributive, procedural, and interactional justice intersect in understanding the consequences of WLB policies and how WLB initiatives and decisions are made. Single workers are routinely required in distributive justice terms to work longer, to take on more responsibilities, and to work more unsocial hours than married counterparts, often sacrificing personal commitments and opportunities to forge intimate relationships. With a focus on procedural justice, decisions are seemingly made based on group membership (e.g. ethnic allegiance) and marital status, creating an unwelcoming and divisive environment where the WLB requirements of singles are rarely met. Misconceptions and inaccurate assessments of the importance of non-work time of single employees, assumptions that singles' work time is more 'available' and that non-work activities are 'inconsequential' (referred to here as a 'time biases') reinforce perceptions of ill-treatment as a form of interactional (in)justice from those in authority. As Beauregard (2014, p. 2) found in a different context, this can potentially trigger backlash attitudes, detrimental to organisations, in the form of demotivation, loss of commitment, and low morale as employees 'reciprocate with organisationally oriented counterproductive work behaviour'.

On a theoretical level, our findings highlight how notions of justice and fairness are integral to understanding WLB. Through the lens of OJ theory, we show the importance of incorporating contextually sensitive misconceptions and biases on the part of employers into our understanding of WLB and how it is arranged. Western-based literature tends to assume that, with equal opportunities and equity practices in place, it is up to the individual, as a responsible agent, to manage a work/non-work interface to suit their needs. This overlooks the significance of differential evaluations on the part of employers on non-work time and the role of favouritism in the distribution of rewards. WLB does not operate in a 'neutral' landscape with 
'neutral' and a-contextual evaluations of employee time. WLB policies are contextually and culturally sensitive concerns. A primacy afforded in Nigerian culture to the family (Mordi et al., 2013) and the associated normative expectation that men and women should eventually relinquish a single status (highlighted by Participant 32 above who referred to parental pressures to marry), may contribute to a 'time biases' where singles' non-work time is viewed as 'inconsequential', to be routinely invaded. We accordingly argue that the current understanding of WLB, largely based on a-contextual assumptions of individual agency in the management of the work/non-work domains, needs to incorporate notions of fairness as well as contextually and culturally sensitive assessments, on the part of employers, of non-work time. 'Time biases', which emerge strongly from our data, contribute to our understanding of singles' experiences of WLB in the study context. This concept may usefully translate to other contexts and to other research on WLB concerns.

\section{Recommendations, Limitations, and Future Research}

As Wilkinson et al. (2018, p. 335) suggest, it is imperative for HR managers to examine the degree to which WLB policies 'cater for those with WLB requirement beyond care responsibilities and how widely WLB issues are framed'. For our participants, the term 'life' covers a broad spectrum of activities, such as recreation, education, leisure, community service, health, and wellbeing, as well as the time to forge intimate relationships. In order to give recognition to this non-work domain, senior management, HR managers, and WLB policy enforcers in the Nigerian healthcare and banking sectors need to implement regulatory and supervisory structures to help promote a culture of inclusiveness and promote awareness of 'time biases' that discriminate against singles.

As Casper and DePaulo (2012) argue, in ensuring that workplaces are family-friendly to all employees regardless of their marital status, two important standards are required: the ethical principles of the American Psychological Association (APA) and those of the Society for Human Resource Management (SHRM). The APA's perspective offers two approaches that can shape managerial decisions when supporting diverse WLB needs. The first approach is to uphold the principles of justice and equity with specific reference to fair rights given to all beneficiaries of WLB services through the use of trained psychologists. The second ethical principle of APA focuses on ensuring that WLB practitioners respect the rights and dignity of their employees and acknowledge their rights to privacy and confidentiality when dealing with WLB requests.

Concerning SHRM's principle, Casper and DePaulo (2012, p. 225) give similar weight to recognising the 'uniqueness and intrinsic self-worth of every individual, ensuring an environment of inclusiveness and commitment to diversity in the organisations we serve, and developing, administering ...policies and procedures that foster consistent and equitable treatment for all'. In practical terms, HR practitioners and managers in the Nigerian healthcare and banking sectors should take these ethical recommendations into consideration with the aim of creating a singles-friendly organisational culture. In addition, it will be worth engaging more meaningfully with the impact of socio-cultural beliefs and how they influence values ascribed to WLB interpretations.

Despite the study making important contributions to the field by examining WLB challenges among an understudied work group, some limitations of the study have been identified that should be addressed in future research. Firstly, this study is limited to investigating the WLB of singles in banking and medical careers. These are highly respected and demanding whitecollar jobs in Nigeria and future studies might consider whether different WLB concerns arise from singles in other work, including manufacturing, sales, or casual employments. Secondly, 
our study focused on heterosexual, 'never-married' professionals. The experiences of this group are likely to differ from other categories of single workers, such as childless divorced people, widows, and even partners who have no children. Furthermore, non-heterosexual families (i.e. single gays, lesbians, bisexuals, and transgender persons) without care responsibilities are diverse samples that could be considered in future research.

\section{References}

Abubaker, M. and Bagley, C. (2016), "Work-life balance and the needs of female employees in the telecommunications industry in a developing country: A critical realist approach to issues in industrial and organisational social psychology", Comprehensive Psychology, Vol. 5, No. 1, pp. 1-12.

Adegbaju, A. A. and Olokoyo, F. O. (2008), "Recapitalization and banks' performance: A case study of Nigerian banks", African Economic and Business Review Vol. 6, No. 1, pp. 1-27.

Adisa, T., Mordi, C., and Osabutey, E. (2017), "Exploring the implications of the influence of organisational culture on work-life balance practices: Evidence from Nigerian medical doctors", Personnel Review, Vol. 46, No. 3, pp. 454-473.

Agarwal, S. and Lenka, U. (2015), "Study on work-life balance of women entrepreneurs review and research agenda", Industrial and Commercial Training, Vol. 47, No. 7, pp. 356362.

Beauregard, T. A. (2014), "Fairness perceptions of WLB initiatives: Effects on counterproductive behaviours", British Journal of Management, Vol. 25, No. 4, pp. 772-789.

Bloom, M. (2004), "The ethics of compensation systems", Journal of Business Ethics, Vol. 52, No. 2, pp. 149-152.

Bowen, G. A. (2008), "Naturalistic inquiry and the saturation concept: a research note", Qualitative Research, Sage Publication, Vol. 8, No. 1, pp. 137-152.

Braun, V., and Clarke, V. (2006) 'Using thematic analysis in psychology', Qualitative Research in Psychology", Vol. 3, No. 2, pp. 77-101.

Brummelhius, L. L. T. and Van Der Lippe, T. (2010), "Effective work-life balance support for various household structures", Human Resource Management, Wiley Interscience, Vol. 49 No. 2, pp. 173-193.

Brough, P. and Kalliath, T. (2009), "Work-family balance: theoretical and empirical advancements", Journal of Organisational Behaviour, Vol. 30, pp. 581-585.

Casper, W. J. DePaulo, B. (2012), A new layer to inclusion: Creating singles-friendly work environments. In N. Reilly., M.J. Sirgy, and C. Gorman (eds.) Work and Quality of Life: Ethical Practices in Organisations. International Handbooks of Quality of Life, Springer Science, pp. 217-233.

Casper, W. J., Marquardt, D. J., Roberto, K. J. and Buss, C. (2016), The hidden family lives of singles adults without dependent children. In T. Allen \& L. Eby (eds). The Oxford Handbook of Work and Family. (pp. 182-195).

Chandler, J., Williams, M., Maconachie, M., Collett. T. and Dodgeon, B. (2004), 'Living alone: its place in household formation and change', Sociological Research Online, Sage, Vol. 9, No. 3. 
Clark, M., Koch, L. and Hill, E. (2004), "The work-family interface: Differentiating balance and fit”, Family and Consumer Sciences Research Journal, Vol. 33, No. 2, pp. 121-40.

Clark, S. C. (2000), "Work-life border theory: A new theory of work/family balance", Human Relations, Vol. 53, No. 6, pp. 747-770.

Cole, N. and Latham, G. (1997), "Effects of training in procedural justice on perceptions of disciplinary fairness by unionised employees and disciplinary subject matter experts", Journal of Applied Psychology, Vol. 82, No. 5, pp. 699-705.

Collins, G. (2008), One singular sensation, New York Times, December 4, p. 43.

Creswell, J. W. (2013). Research design: Qualitative, quantitative, and mixed methods approaches. Sage publications.

Eby, L. T., Allen, T. D. and Noble, C. L. (2004), Perceptions of singles and single parents: A laboratory experiment", Journal of Applied Social Psychology, Vol. 34, No. 7, pp. 1329-1352.

Erdogan, B. (2002), “Antecedents and consequences of justice perceptions in performance appraisals”, Human Resource Management Review, Vol. 12, No. 4, pp. 555-578.

Feeney, M. K. and Stritch, J. M. (2017), "Family-friendly policies, gender, and work-life balance in the public sector", Review of Public Personnel Administration, Sage Journal, pp. 127.

Gatrell, C. J. and Cooper, C. L. (2008), "Work-life balance: working for whom? European Journal of International Management”, Vol. 2 No. 1, pp. 71-86.

Greenberg, J. (1987), "A taxonomy of organisational justice theories", Academy of Management Review, No. 12 No. 1, pp. 9-22.

Greenhaus, J. H. and Powell, G. N. (2006), "When work and family are allies: A theory of work-family enrichment", Academy of Management Review, Vol. 31, No. 1, pp. 72-92.

Guba, E. and Lincoln, Y. S. (1994), Competing paradigms in qualitative research, in Denzin, N. K. and Lincoln, Y. S. (Eds), Handbook of Qualitative Research, Sage, Newbury Park, CA.

Hofstede, G. (2001). Culture's Consequences: Comparing Values, Behaviours, Institutions and Organizations across Nations. Thousand Oaks, CA: Sage.

Kelly, E. L., Moen, P., Oakes, J. M., Fam, W., Okechukwu, C., Davis, K. D. etal., (2014), "Changing work and non-family conflict: Evidence from work, family and health network", American Sociological Review, Vol. 79, No. 3, pp. 485-516.

Kirfi, M. M. W. and Abubakar, A. B. (2014), "Job satisfaction of employees in Nigerian banks: A study of Access Bank Plc, Sokoto, Nigeria”, Journal of Human Resource, Vol. 2, No. 8, pp. $1-13$.

Kossek, E. E., Rudeman, M. N., Braddy, P. W. and Hannum, K. M. (2012), "Work-nonwork boundary management profiles: A person-centred approach", Journal of Vocational Behaviour, Vol. 81, No. 1, pp. 112-128.

Kovačević, I., Zunic, P. and Mihailović, D. (2013), "Concept of organisational justice in the context of academic achievement", Journal for Theory and Practice Management, Vol. 18, No. 69 , pp. 37-45. 
Lewis, S. and Cooper, C. (2005) Work-Life Integration: Case Studies of Organisational Change, Chichester: Wiley.

Lewis, S. and Humbert, A. L. (2010). Discourse or reality? Work-life balance, flexible working policies and the gendered organization. Equality, Diversity and Inclusion: An International Journal, Vol. 29, No. 3, pp. 239-254.

Manfredi, S. and Holliday, M. (2004). Work-life balance: An audit of staff experiences at Oxford Brookes University. The Centre of Diversity Policy Research: Oxford Brookes University.

Miles, M. B. and Huberman, A. M. (1994). Qualitative data analysis, Beverly Hills, CA: Sage.

Mordi, C., Mmieh, F. and Ojo, S. I. (2013), “An exploratory study of managers, perspective of work-life balance in Nigeria: A case analysis of the Nigerian banking sector", Thunderbird International Review, Vol. 55, No. 1, pp. 55-75.

Mushfiqur, R., Mordi, C., Oruh, E. S., Nwagbara, U., Mordi, T. and Turner, I. M. (2018), "The impacts of work-life-balance (WLB) challenges on social sustainability: The experience of Nigerian female medical doctors”, Employee Relations, Vol. 40 No. 5, pp. 868-888.

National Population Commission of Nigeria. (2017), State population, www.population.gov.ng/index.php/state-population. (Accessed on 09/10/2018).

Nelson, M. F. and Tarpey, R. J. (2010). Work scheduling satisfaction and work life balance for nurses: the prception of organizational justice. Academy of Health Care Management Journal, $6(1), 25$.

Nippert-Eng, C. E. (1996), Home and work, Chicago, IL: The University of Chicago Press.

Özbilgin, M. F., T., Beauregard, T. A., Tatli, A. and Bell, M. P. (2010), "Work-Life, Diversity and Intersectionality: A Critical Review and Research Agenda", International Journal of Management Reviews, Blackwell Publishing, pp. 1-22.

Patton, M. Q. (2015), Qualitative research and evaluation methods: Integrating theory and practice. (4th ed.), Los Angeles: Sage.

Pratt, M. G., Rockmann, K. W. and Kaufmann, J. B. (2006), "Professional identity: The role of work and identity learning cycles in the customization of identity among medical residents", The Academy of Management Journal, Vol. 49, No. 2, pp. 235-262.

Rajadhyaksha, U. (2012), "Work-life balance in South East Asia: the Indian experience", South Asian Journal of Global Business Research, Vol. 1, No. 1, pp.108-127.

Rotondo, D. M., and Kincaid, J. F. (2008), "Conflict, facilitation, and individual coping styles across the work and family domains”, Journal of Managerial Psychology, Vol. 23, No. 5, pp. 484-506.

Saunders, M., Lewis, P. and Thornhill, A. (2012), Research methods for business students (6th Ed.). London, England: Prentice Education Limited.

Visser, F. and Williams, L. (2006), Work-life balance: Rhetoric Versus Reality, Work Foundation, London.

Wilkinson, K., Tomlinson, J. and Gardiner, J. (2017), "Exploring the work-life challenges and dilemmas faced by managers and professionals who live alone", Work, Employment and Society, Vol. 31, No. 4, pp. 640-656. 
Wilkinson, K., Tomlinson, J. and Gardiner, J. (2018), "The perceived fairness of work-life balance policies: A UK case study of solo-living managers and professionals without children", Human Resource Management Journal, Vol. 18, No. 2, pp. 325-339.

Yakes, L. (2018), "Sharing, households and sustainable consumption", Journal of Consumer Culture, Vol. 18, No. 3, pp. 433-452.

Yeung, W. J. and Cheung, A. K. (2014), "Living alone: One-person households in Asia", Demographic Research, Vol. 32, Article 40, pp. 1099-1112.

Zheng, C., Molineux, J., Mirshekary, S. and Scarparo, S. (2015), "Developing individual and organisational work-life balance strategies to improve employee health and wellbeing", Employee Relations, Vol. 37, No, 3, pp. 354-379.

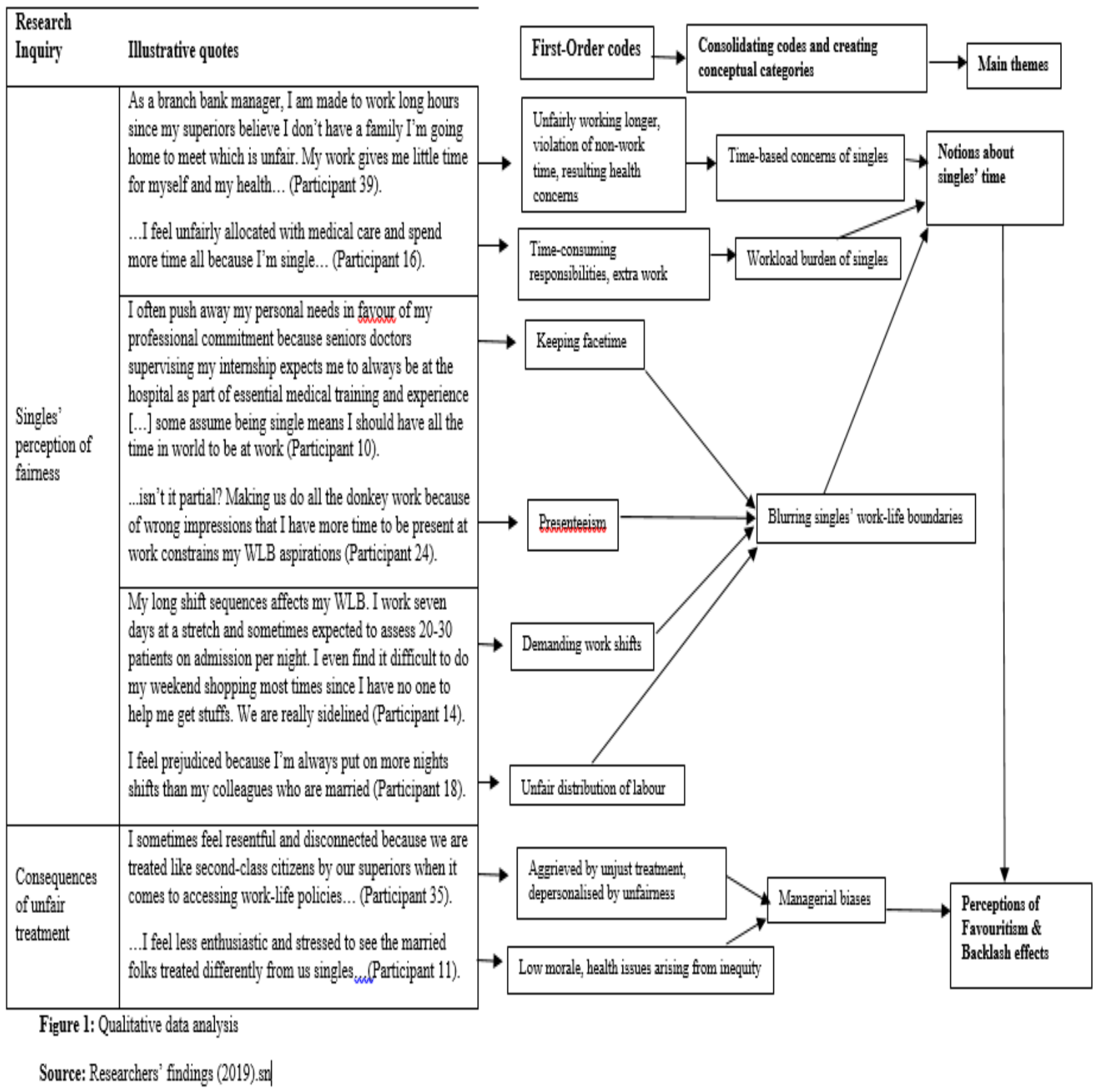


